\title{
Ascaris lumbricoides: A Review of Its Epidemiology and Relationship to Other Infections
}

\author{
Marilyn E. Scott \\ Institute of Parasitology, McGill University, Ste-Anne-de-Bellevue, Que., Canada
}

\author{
Key Words \\ Ascaris lumbricoides · Epidemiology, infection • Water \\ scarcity $\cdot$ Cross-transmission $\cdot$ Immunology $\cdot$ Infections, \\ concurrent
}

\begin{abstract}
This review highlights advances made since 2004 in understanding the epidemiology of infection and the interactions between Ascaris lumbricoides and other concurrent infections. As water scarcity increases, untreated wastewater is increasingly used to irrigate crops, thus increasing the risk of transmission. New methods to detect and inactivate Ascaris eggs in water, soil and food are described. The association between pig ownership and Ascaris infection in humans may represent cross-transmission as hybridization among the pig and human ascarids occurs more frequently than previously believed. Geospatial analyses have successfully predicted infection levels both at a regional level (based on vegetation indices, temperature and humidity) and within communities (based on social and environmental factors). The interpretation of antibody and cytokine responses to Ascaris is becoming clearer, as researchers recognize the role of antigen type, age, the history of Ascaris and other infections. The considerable interest emerging on the interactions between Ascaris and other infections (helminths, malaria, HIV, tuberculosis) and allergy is explored. The impact of concurrent infection on the design of control strategies is discussed including the benefits arising from combination therapies and the evi-
\end{abstract}

dence that intestinal nematodes impair the efficacy of childhood vaccines. Finally, recommended areas for future research are identified.

Copyright $\odot 2008$ Nestec Ltd., Vevey/S. Karger AG, Basel

\section{Introduction}

Over the past century, advances in our understanding of virtually all aspects of parasitic disease have contributed to reducing the prevalence of parasitic infection in many populations. Regrettably, however, these infections still remain embedded within the daily life of the majority of impoverished populations living in the tropical and subtropical regions of the world. At center stage are the three common soil-transmitted, intestinal nematodes, Ascaris lumbricoides, Trichuris trichiura and hookworm, that are estimated to infect 1.4, 1 and 1.2 billion people, respectively, representing about $25 \%$ of the world's population [1]. Perhaps more important than the numbers infected are the estimates of the resulting disease burden of $10.5,6.4$ and 22.1 million disability adjusted life years, respectively [2].

This review focuses on $A$. lumbricoides (referred to henceforth by the generic designation of Ascaris), and provides an overview of the major research developments since 2004. It also demonstrates the need to consider parasitic infections in a much more holistic manner than is traditional in both the research and clinical setting by ar-

\section{KARGER}

Fax +41613061234

E-Mail karger@karger.ch

www.karger.com (c) 2008 Nestec Ltd., Vevey/S. Karger AG, Basel

0517-8606/08/0661-0007\$24.50/0

Accessible online at:

www.karger.com/ane
Marilyn E. Scott

Institute of Parasitology

McGill University (Macdonald Campus), 21111 Lakeshore Road

Ste-Anne-de-Bellevue, Que. H9X 3V9 (Canada)

Tel. +1 514398 7966, Fax +1 514398 7857, E-Mail marilyn.scott@mcgill.ca 
guing that one person may well be concurrently infected with a vast array of other helminth, protozoan, bacterial, and viral infections, and that these organisms interact with each other and their host in ways that critically affect the design of prevention and control interventions.

\section{Life History and Epidemiology}

\section{Life Cycle and Pathology}

Ascaris is transmitted by the ingestion of eggs [for reviews, see 1,3$]$. These eggs hatch, larvae penetrate through the intestine and migrate through the portal vessels to the liver and lungs where they are coughed up and swallowed, a process that takes several weeks. After the worms return to the intestine, they mature as adult male and female worms, typically measuring about 20 and $30 \mathrm{~cm}$ in length, respectively.

The migratory phase is responsible for inflammatory and hypersensitivity reactions in the lung, including pneumonitis and pulmonary eosinophilia. Pathology induced by the adult worms includes malabsorption, intestinal obstruction, and invasion of the bile duct or appendix, leading to acute pancreatitis and appendicitis. Ascaris has also been associated with impaired cognitive function. Although much of the early evidence is quite weak [4], Ezeamana et al. [5] found that Filipino children (7-18 years old) with moderate and high intensity Ascaris infection had lower responses in cognitive tests of memory compared with uninfected children, after controlling for nutritional status, socioeconomic indicators and other helminth infections.

The period from ingestion of eggs to their detection in feces ranges from 10 to 11 weeks, and adult worms live for 1-2 years. During this time, adults mate and Ascaris eggs are passed in the feces. Fecundity estimates vary considerably among geographical regions, ranging from 10 to 220 eggs per female worm per gram of feces [6]. Ascaris eggs are more resistant to desiccation than hookworm or Trichuris eggs. Given favorable environmental conditions, they have been reported to survive for up to 15 years [3]. They are also very sticky [7], and attach easily to fruit, vegetables, soil and dust particles, children's toys, currency notes, flies and cockroaches [3, 8-10].

\section{Risk Factors Associated with Transmission}

Transmission of Ascaris eggs is typically associated with accidental ingestion of soil [11], but deliberate ingestion of soil and ingestion of contaminated vegetables, greens and fruit are also important. Purposeful ingestion of soil, 'pica', is a significant risk factor for Ascaris in children [12], and in pregnant and lactating women in some populations. In western Kenya, $45.7 \%$ of pregnant women surveyed were geophagous, consuming an average of $45.4 \mathrm{~g}$ of earth/day during mid-term pregnancy and $25.5 \mathrm{~g} /$ day at 6 months postpartum [13]. Following mebendazole treatment at 28-32 weeks of gestation, Ascaris prevalence (percent infected) was significantly higher in geophagous women at 3 and 6 months postpartum compared with those not consuming earth [14], indicating more rapid re-infection among those eating soil. Interestingly, prevalence increased more rapidly in women who preferred termite mound earth that is typically found around the home, compared with those consuming other soft earths that are normally purchased and thus less likely to be contaminated with Ascaris eggs [14]. Ingestion of termite mound earth has also been reported as a risk factor for Ascaris among grade 3 children in South Africa [12].

Evidence from several studies suggests that the risk of transmission due to contaminated food may be increasing as pressures to minimize the use of artificial fertilizers and to conserve water indirectly promote re-use of wastewater as an organic fertilizer and for irrigation of field crops and hothouse gardens [15]. In Morocco, Ascaris prevalence was significantly higher in children living in a peri-urban area where urban wastewater was used for irrigation (13.3\%), compared with children of similar living standards but where well water was used for irrigation (1.7\%) [16]. A survey of vegetables from urban markets in Ghana revealed Ascaris eggs on $60 \%$ of lettuce, $55 \%$ of cabbage and $65 \%$ of spring onion samples, with mean helminth egg numbers (including Ascaris, Trichuris, hookworm and Schistosoma) of 1.1, 0.4 and 2.7/g wet weight of lettuce, cabbage and spring onions, respectively [17]. Thus, despite recommendations to the contrary, in situations of water scarcity, where the use of untreated wastewater for irrigation is seen as the only alternative to ensure continuing food production [17], the risk of Ascaris transmission from food sources may be expected to increase.

The set of environmental, social and behavioral predictors of elevated Ascaris egg output are not always consistent across studies, but crowding [18-20], poor education of mothers [18, 20-22], open defecation [20, 22], inadequate water supply [18-20], poverty [18, 20, 22-25], poor nutritional status $[24,26,27]$, use of human biosolids for fertilizers and irrigation [16], geophagy [12], not washing hands before eating [25], pig ownership or livestock breeding $[20,25,28]$, and consumption of raw pork and raw water plants [25] are often reported, depending on the population under consideration (preschool chil- 
dren, schoolchildren, migrant women, street vendors, entire communities).

As one example, Traub et al. [20] surveyed households on tea plantations in India and identified six significant predictors of Ascaris prevalence: age (children), household crowding (more than 6 people per household), employment (tea plantation workers had a higher prevalence than plantation staff), outdoor defecation, ownership of pigs, and low level of education. Three of these (age, crowding and pig ownership) as well as being Hindu were also associated with elevated Ascaris intensity, measured as eggs per gram feces (epg). However, neither employment nor outdoor defecation entered the final model for intensity, likely because they were highly correlated with household crowding and pig ownership, respectively.

The association with pig ownership is intriguing, given the continuing interest in the zoonotic potential of transmission of Ascaris suum from pigs to humans. Pigs may act as mechanical disseminators of Ascaris eggs, as unembryonated $A$. suum eggs that pass through the pig intestine retain infectivity to pigs, and pigs are coprophagous [29]. Although molecular epidemiology indicates that cross-infection is uncommon [30], evidence for hybridization between sympatric pig and human worms [31] has recently been reported. Criscione et al. [31] examined 23 microsatellite loci from 129 Ascaris collected from pigs and humans in China and Guatemala, and from humans in Nepal. Using Bayesian clustering methods to detect host colonization patterns and to identify hybrid worms, their analysis indicated that $4 \%$ of the worms from Guatemala and 7\% of the worms from China were hybrids and they interpreted this to mean that cross-transmission between pigs and humans may occur more often than previously detected [31].

\section{Age Profile}

The epidemiological pattern of Ascaris infection in a community is well documented, and follows a similar pattern in all regions where it is endemic. In large part, the pattern results from the continual ingestion of eggs, leading to superimposition of existing worms and new incoming worms, and to rapid re-infection following drug treatment. Thus, in areas where Ascaris is endemic, individuals are likely to be infected with Ascaris for a large portion of their life.

Infection has been reported in children as young as 5 months of age [32] and both the prevalence and intensity increase rapidly with age. Among Zanzibari infants, the prevalence of Ascaris increased from approximately $7 \%$ in the 5- to 9-month-old children to about $20 \%$ in infants aged 10-11 months [32]. The prevalence and intensity typically peak in the 6- to 10 -year-old age group [33].

Although prevalence usually remains elevated even in the adult population, intensity typically declines in adults [33]. This has been interpreted to result from a combination of reduced contact with eggs, and an accumulated immunological resistance to incoming infection [34]. Recently, a third alternative has been proposed by Galvani [35] who suggests that slow development of resistance with age could result from the antigenic diversity of circulating parasite strains. Interestingly, there are also reports of elevated infection in the elderly [36], and this may be more common than reported, given that most community-based surveys do not identify the elderly as a separate age group in the data analysis. The elderly population is growing in many countries where Ascaris is endemic, and their weakening health and immunocompetence may put them at risk of elevated infection and associated morbidity.

\section{Large Scale Spatial Pattern}

Whereas epidemiological studies in the past have focused primarily on age-related patterns of infection, and occasionally on temporal changes in infection, more recently, interest has shifted to spatial patterns of infection both at the small village-level scale and the large, country-wide scale. Such research has benefited substantially from methodologies in geographic systems analysis, the large spatial databases that are now available, and the ease of use of hand-held geopositioning systems [37, 38]. Vegetation indices are strongly associated with information on temperature and rainfall, both of which explain pockets or entire regions within a country where Ascaris prevalence may be very high or unusually low. For example, a normalized difference vegetation index based on satellite imaging at a $1-\mathrm{km}$ resolution was a significant predictor of both Ascaris infection and re-infection intensity [12]. Brooker et al. [39] demonstrated that land surface temperature and rainfall were important determinants of Ascaris in Uganda. Prevalence was higher in regions where maximum land surface temperatures were less than about $38^{\circ} \mathrm{C}$ and was considerably lower at higher land surface temperatures. In Sri Lanka, Gunawardena et al. [40] found that the total number of days per month with rain (wet days) provided a better correlation with Ascaris intensity and rates of re-infection than total rainfall per month or mean monthly temperature. Prevalence typically does not exceed $10 \%$ unless annual rainfall exceeds 1,000-1,400 mm, depending on the local soil conditions [39]. Interestingly, in an overview of climatic factors affecting the species diversity of human pathogens, 
Guenier et al. [41] found that ranges in monthly temperature and maximum range in precipitation were better predictors of latitudinal differences in human helminth parasite assemblages than mean values.

Considerable differences in prevalence and intensity can also exist within a much finer spatial scale. For example, Ascaris prevalence among 9-12 year olds in 43 schools in the Forest Zone of Pernambuco, Brazil, ranged from 6.7 to 55\% [42]. In Cameroon, the average Ascaris epg in 4- to 11-year-old children was almost twice as high in one village compared with another village only $6 \mathrm{~km}$ away, despite the apparent similarity between the villages [43]. At this spatial scale, environmental and lifestyle factors are likely to play a larger role than rainfall and temperature [39]. For example, researchers in Brazil have developed a geospatial model that used data on mother's education, family income, use of filtered water, and number of people per room to effectively describe the regions at risk of Ascaris infection in children aged 1-9 years at a resolution of $30 \mathrm{~m} \mathrm{[18].}$

\section{Aggregation within Communities}

In addition to the typical age-prevalence and age-intensity profiles, Ascaris infection is aggregated within the population, such that the majority of worms are found in a small proportion of the host population [33]. This aggregation is believed to result from heterogeneity among hosts in a variety of factors that influence rates of exposure to eggs in the environment and the establishment and survival of the parasites.

Given that so many of the risk factors for Ascaris transmission, establishment and survival are common within the family or household, it is not surprising that Ascaris is also aggregated at the household level. Household clustering accounted for 21 and $39 \%$ of the variance in heavy infection (defined as $>10,000 \mathrm{epg}$ ), respectively, in urban and rural regions of the municipality of Americaninhas, Brazil [44]. In southwest Uganda, 51\% of total variance in the 90th percentile of epg was explained by household in a community-wide survey [45], and in China household accounted for $31.7 \%$ of the risk of Ascaris infection [46].

Efforts continue to determine the role of genetic factors in susceptibility to Ascaris infection, especially following a study in Nepal indicating that $30-50 \%$ of the variability in Ascaris worm burden could be attributed to genetic pedigree [47]. Follow-up genome scans in the same population revealed genes on chromosomes 1 and 13 that were significantly linked with Ascaris epg [48], at least one of which may be involved with B cell activation. They also detected significant heritability of cytokines
IL-4, IL-5, IL-10, IFN- $\gamma$, and of the ratios of IL-4/IFN- $\gamma$ and of IL-10/IFN- $\gamma$, indicators of T-regulatory processes [49]. Ellis et al. [46], however, were unable to detect a significant genetic component to risk of Ascaris infection in their study of familial aggregation of helminth infections in China, though the use of prevalence (not intensity) data may be an explanation. Genetic differences in the STAT6 gene, which is involved in Th2 immune signaling, have also been linked with Ascaris intensity [50].

Aggregation has important consequences as those few heavily infected individuals are more likely to suffer the clinical consequences of the infection. Even though egg production per female worm declines as worm burdens increase [6], this density-dependent process is not sufficient to reduce net egg output from heavily infected individuals below that of lightly infected individuals, and thus the aggregated dispersion of Ascaris results in the few heavily infected individuals playing a key role in contaminating the environment with eggs. Also, high levels of aggregation are predicted to increase the stability of the host-parasite association, making the parasite population more resilient to external forces, such as drug control, with the predicted consequence that highly aggregated infections will be more difficult to eradicate [51].

Finally, many of the factors that make an individual at risk of heavy infection do not change over a lifetime, and as a consequence certain individuals are predisposed to heavy infection [52]. This means that, at a community level, those individuals with a high egg output prior to drug treatment are likely to rapidly regain large numbers of worms following treatment, whereas those with low epg are likely only to regain a few worms.

\section{Immunology}

\section{Immune Responses to Ascaris}

Ascaris induces a strong humoral response characterized by elevated IL-4, IL-5, eosinophilia and Ascaris-specific IgE, hallmarks of a Th2 immune response [53; for review, see 54]. Although correlations between antibody titers and egg production are not always detected [55], there is evidence that individuals with high Ascaris-specific antibody titers and Th2 cytokines have lower epg, suggesting that continuing exposure to Ascaris eggs from the environment acts as an ongoing booster to maintain elevated protective immune responses, and that individuals with low responses tend to have higher egg output, indicating a weakness in their ability to control the infection [56-58]. 

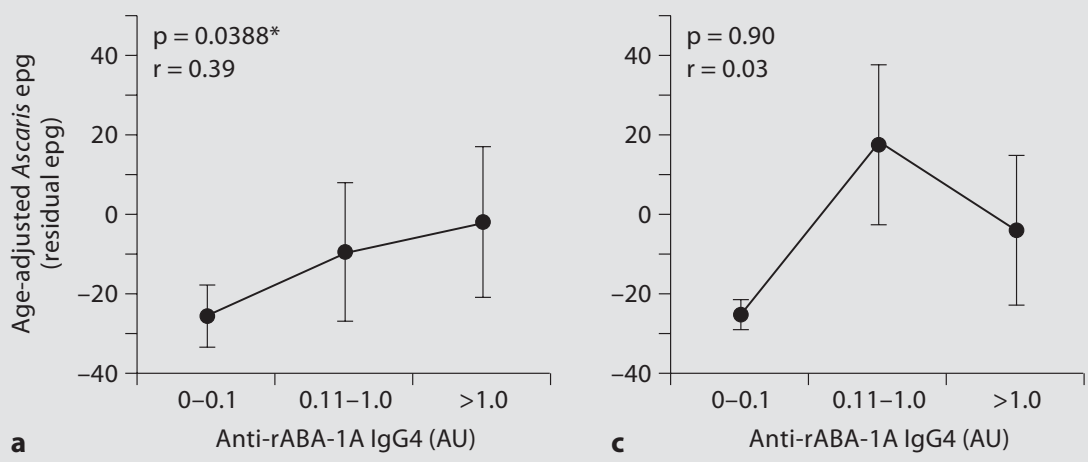

Fig. 1. Relationship between antibody responses to recombinant Ascaris allergen (rABA-1A) and age-adjusted Ascaris eggs per gram (epg) in 4-11 year olds (a, b) and 12-36 year olds (c, d) from Cameroon. Data on IgG4 responses (a, c) and IgE responses $(\mathbf{b}, \mathbf{d})$ are shown. Whereas IgG4 titers are elevated as infection intensity increases in the 4- to 11-year-old age group, IgE titers decline with increasing intensity among the 12-36 year olds. Spearman's rho (r) and $\mathrm{p}$ values are reported. ${ }^{*} \mathrm{p}<$ 0.05 . Reprinted with permission from Turner et al. [34].
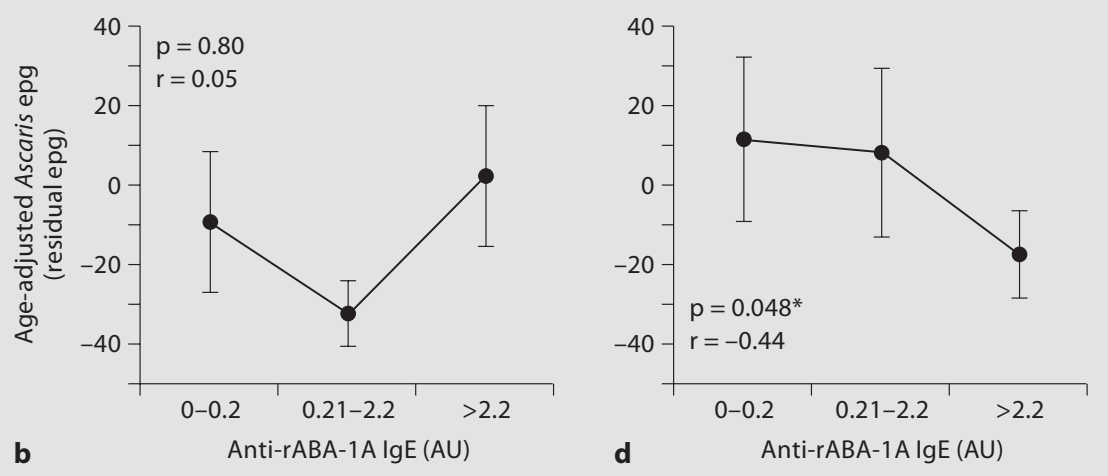

It appears that at least three factors account for the differing results among studies: type of antigen, isotype of antibody response, and age $[34,59]$. There appears to be no association between infection intensity and either $\operatorname{IgE}$ or IgG4 responses to crude antigens [34]. However, the IgE-specific response to a recombinant form of an Ascaris allergen (rABA-1A) is associated with resistance to $A s$ caris. IgE titers to rABA-1A decreased with increasing Ascaris intensity in 12- to 36-year-old participants from Cameroon [34], as shown in figure 1, and elevated $\operatorname{IgE}$ responses to Ascaris glycolipids were also detected in lightly infected children from Cameroon, compared with heavily infected children and uninfected European controls [59]. In contrast, IgG4 titers to rABA-1A increased with increasing Ascaris intensity in 4- to 11-year-old children (fig. 1) [34] as did the IgG4 response to proteins in the Indonesian children [59]. Perhaps of most interest is the observation that the ratio of $\operatorname{IgG} 4$ to $\mathrm{IgE}$ in response to rABA-1A increased with Ascaris epg [34], indicating that IgG4 may either block the IgE response which is necessary for resistance to Ascaris or interfere with class switching of IgG4 to IgE production. Turner et al. [34] suggested that these responses may be modulated by the regulatory processes involving IL-10.
In the same population, Jackson et al. [57, 58] examined cytokine responses prior to and 8-9 months after deworming. Using a principal components analysis which enabled them to collapse large amounts of data into a few principal variables, they were able to demonstrate that general susceptibility to either Ascaris or Trichuris was negatively associated with Th2-dominated responses (driven by IL-13) in 4- to 13-year-old children as shown in figure 2, but not in the 14- to 57-year age group [57]. They also showed that resistance to re-infection was positively associated with a Th2-dominated response, driven primarily by IL-5 [57]. When they analyzed the data separately for the two parasites [58], it became evident that the cytokine expression patterns were species specific. For Ascaris, a negative association was detected between Th2dominated responses (driven by IL-13) and epg before treatment but not after treatment. In contrast, Trichuris epg was negatively associated with Th2-dominated responses only after treatment, and involved both IL-13 and IL-5, as shown in figure 3 . The studies by Williams-Blangero et al. [47-49] provide clear evidence that at least some variability in immune responsiveness has a genetic component (see Aggregation within Communities, p. 10).

It is important to note that nematodes also have a suppressive effect on the host immune response. A. suum re- 

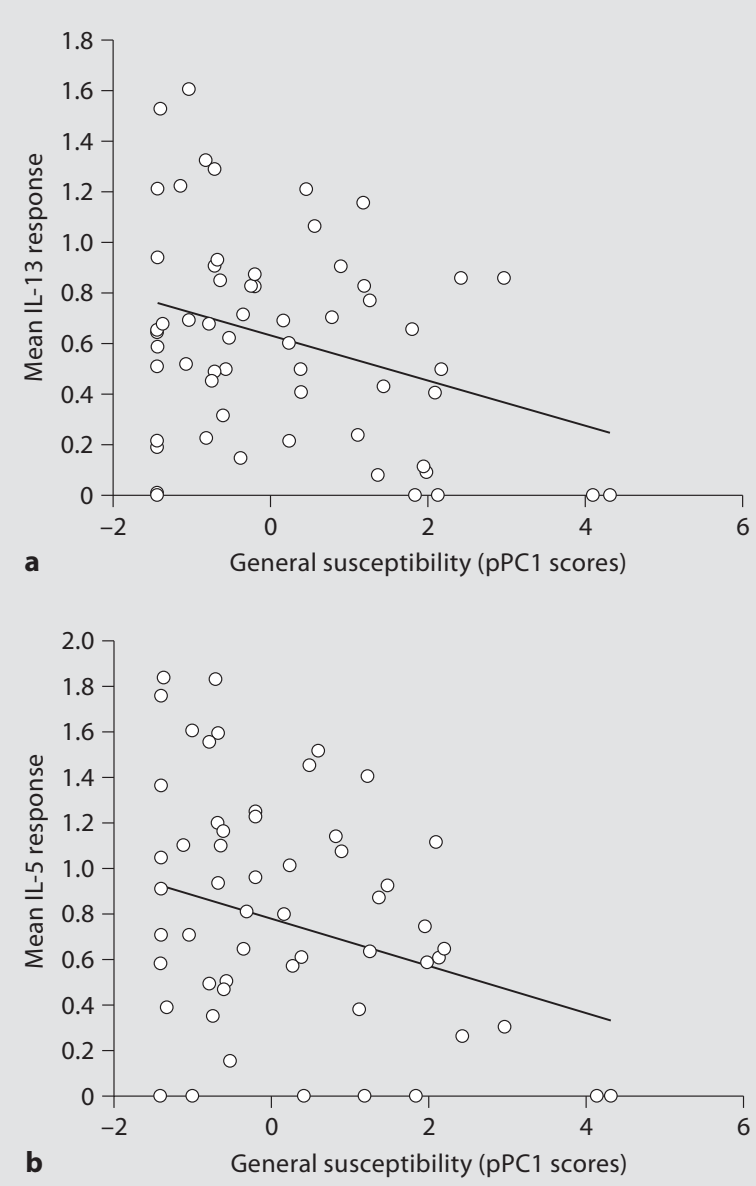

Fig. 2. Relationship between cytokine responses and susceptibility to Ascaris and Trichuris infection in 4- to 13-year-old children from Cameroon based on principal components analysis. The $\mathrm{x}$ axis captures a set of data reflecting general susceptibility to one or the other of the nematodes, based on fecal egg output. The y axis shows the average IL-13 (a) and IL-5 (b) standardized data based on the ex vivo response to 3 parasite-derived antigens ( $A s$ caris lumbricoides, Trichuris muris and T. muris excretory-secretory antigen). IL-13 declines with increasing general susceptibility score $\left(\mathrm{F}_{1,60}=5.80, \mathrm{p}=0.019\right)$ and the IL-5 response shows a similar but nonsignificant trend $\left(\mathrm{F}_{1,58}=3.70, \mathrm{p}=0.059\right)$. Reprinted with permission from Jackson et al. [57].

leases potent immunosuppressive molecules that interfere with antigen presentation of dendritic cells [60]. The purified proteins maintain their ability to inhibit T-cell-dependent antibody production and to suppress both Th1 and Th2 responses through modulation of IL-4 and IL-10 [61]. Similar processes are likely to occur in human Ascaris infections as well. Thus, variability in antibody titers and cytokine levels may be, in part, related to the responsiveness of the host to such immunosuppressive molecules.
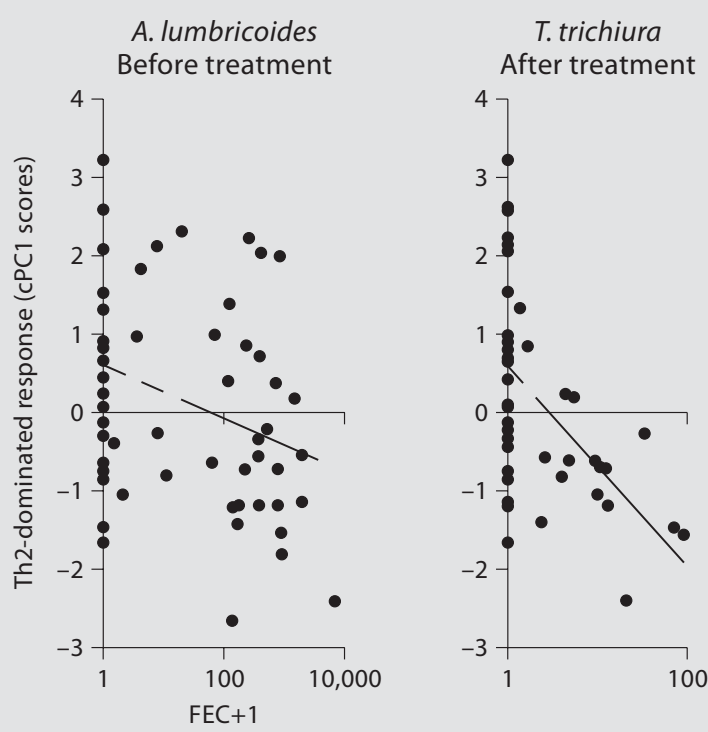

Fig. 3. Relationship between Th2-dominated cytokine responses of 4- to 13-year-old children from Cameroon and Ascaris lumbricoides log epg prior to treatment or Trichuris trichiura log epg 8-9 months after treatment, based on a principal components analysis. The y axis captures a set of data predominantly reflective of Th2 cytokines. Ascaris epg was negatively associated with the Th2dominated response prior to drug treatment $\left(\mathrm{F}_{1,59}=5.95\right.$, $\mathrm{p}=0.0018$ ) but not after re-infection. In contrast, Trichuris epg was not associated with the Th2-dominated response prior to treatment, but was negatively associated after treatment $\left(\mathrm{F}_{1,45}=6.38\right.$, $\mathrm{p}=0.015)$. Reprinted with permission from Jackson et al. [58].

\section{Ascaris and Allergy}

There is considerable recent evidence that the Th2 environment induced by Ascaris infection is beneficial in preventing and/or controlling a range of atopic and autoimmune conditions where an aggressive Th1 response is pathogenic [50]. This is believed to result either from crossregulation between $\mathrm{Th} 1$ and Th2 response phenotypes or from the influence of T-regulatory cytokines [62], and may depend on the specific STAT6 haplotype involved in Th2 immune signaling [50]. Atopy refers to clinical manifestations of IgE-mediated hypersensitivity, including allergic rhinitis (hay fever), eczema, asthma and various food allergies, and is defined operationally as the presence of either a positive skin test to extracts of inhaled allergens or the presence of allergen-specific IgE in serum.

The interaction between Ascaris and atopic diseases differs depending on whether current infection or history of infection with Ascaris is considered [63]. There is also evidence that the interaction is modified by the presence of other infections including active tuberculosis 
[64]. Based on a recent study in South Africa where the prevalence of Ascaris in 6- to 14-year-old children was only $14.8 \%$, elevated Ascaris-specific IgE (but not Ascaris eggs in stool) increased the risk of positive skin tests to a wide range of aeroallergens as well as to atopic rhinitis and asthma, but this effect was not detectable in children who had active tuberculosis [64]. In Ecuador, researchers have shown a strong negative association between allergen skin test reactivity and Ascaris infection [65]. In mice, acute $A$. suum infection was found to exacerbate allergic symptoms whereas a chronic infection was protective [66]. A similar distinction has been observed in human studies. A meta-analysis of data on eggs in stool [67] revealed that current infection was associated with an increased risk of asthma, whereas a retrospective cohort study in East Germany demonstrated that children with a history of intestinal worm infections (Ascaris and/or pinworms) had reduced atopic and non-atopic eczema, as well as a reduced risk of allergic sensitization to common aeroallergens [62].

One intriguing recent observation [68] may provide an alternative explanation for the association between Ascaris and many allergic responses, because Ascaris shares a common antigen with several environmental allergens. Arruda and Santos [68] found that tropomyosin occurs in a wide range of invertebrates, including Ascaris, and that IgE against this molecule is found in over $50 \%$ of individuals living in regions where Ascaris is endemic.

\section{Ascaris, Growth and Malnutrition}

Malnutrition impairs immune responses which in turn can increase susceptibility to infection [for review, see 69, 70]. The negative effects of Ascaris on the absorption of vitamin A and fat, protein, and certain sugars, together with anorexia induced by infection, account for the poor growth of Ascaris-infected children, and the improved growth that is evident following deworming [70, 71]. In fact, parents report that deworming increases the activity and appetite of their children [72]. In a recent study in Panama, rates of re-infection with Ascaris were reduced by providing vitamin A supplements to preschool children [27]. This conclusion is consistent with observations in Mexico where Ascaris-infected children less than 2 years of age who received vitamin A supplementation had higher fecal concentrations of IL- 4 than infected children who received a placebo [73]. These studies are encouraging as they demonstrate the scope of health benefits resulting from nutritional interventions.
Ascaris infection in infants is understudied. Nevertheless, evidence is emerging to suggest that infants as young as 5 months of age [32] are infected and that infection in these infants is important. Stoltzfus et al. [74] recently demonstrated that a reduction in Ascaris prevalence and intensity by treating with mebendazole resulted in more dramatic improvement in growth of children aged 6-30 months than in children from 30 to 71 months of age, despite the lower baseline infection in the younger children. In regions where infection is very common, it is probable that children will become infected before they are able to rely on their own immune system. Also, the presence of a few worms in infants may be more clinically significant than the same number of worms in older children.

In many developing countries, a new form of malnutrition is emerging - obesity. Among schoolchildren living on Pacific Islands where Ascaris, Trichuris and hookworm are endemic, helminth-infected children had a significantly lower risk of elevated body mass index, an indicator of overweight [19]. This survey of 27 schools found 6 schools where more than $10 \%$ of children were overweight, and 5 other schools where more than $10 \%$ of children were stunted. Public health initiatives now must fight both undernutrition and overnutrition. There is a critical need to understand interactions between overnutrition and parasitic infection, and to consider the most appropriate mix of interventions in populations where undernutrition and overnutrition co-occur.

\section{Diagnosis}

\section{Eggs in Stool}

Among the variety of techniques for detecting Ascaris infection, observation of eggs in stool samples is most commonly used. Studies that require an estimate of intensity typically use the Kato Katz technique. It is important to note that unfertilized eggs are often missed when using the Kato Katz technique [32], and thus a concentration technique may be more appropriate in infants who may have single sex infections or for monitoring re-infection shortly after deworming programs. Also, in areas where hookworm is present, samples must be examined within a few hours after preparation if results on hookworm are to be considered reliable. Alternatively replacing malachite green with a nigrosin/eosin solution has been recommended as this allows hookworm eggs to remain visible on the Kato Katz slides [75].

Whereas epidemiological studies in the past often provided data only on the prevalence of infection, there has 
been increasing appreciation of the importance of data on the intensity of infection. Researchers have responded by more consistently providing this information. However, many report intensity according to the $\mathrm{WHO}$ categories of light $(<5,000 \mathrm{epg})$, moderate $(5,000-50,000 \mathrm{epg})$ or heavy $(>50,000 \mathrm{epg}$ ) [6]. Based on the review by Hall and Holland [6] that demonstrated considerable geographic variability in egg production per female Ascaris, it is not clear that these WHO categories are appropriate in all regions, as there is a risk that high worm burdens may be misrepresented as moderate or even low intensity infections.

\section{Immunodiagnosis}

When information on the history of exposure to Ascaris is more relevant than the presence of current infection [63], Ascaris-specific IgE may be a useful marker of previous exposure, and more relevant than eggs in stool samples in studies concerned with the effect of Ascaris on immunocompetence [76] (see Ascaris and HIV, p. 16).

\section{Eggs in Wastewater}

The development of new diagnostic approaches has focused on real-time PCR methods of detecting eggs in the environment. Pecson et al. [77] have had good success using quantitative PCR of an internally transcribed spacer region of ribosomal DNA that provides results comparable to traditional microscopy in assessing the success of heat, UV and ammonia treatment in removing Ascaris eggs from sludge.

\section{Control Strategies}

The goal of most control programs [for review, see 78] is to reduce the intensity of infection because it is argued that the few heavily infected children are not only at higher risk of infection-induced morbidity, but also that they are the major contributors to transmission because they pass such a large number of eggs in their feces. Interestingly a recent theoretical study, that makes more explicit account of the dispersion of worms among individuals, suggests that reducing intensity may not have as dramatic an effect on reducing transmission as is commonly understood [51], due to density-dependent mechanisms within the parasite population that make the relationship between worm burden and egg production highly nonlinear.

\section{Anthelmintics}

By far the most common method for controlling Ascaris is treatment with anthelmintic drugs. A single oral dose of albendazole reduces Ascaris epg by more than $95 \%$ and is safe for use in mass treatment campaigns [79]. Furthermore it also reduces Trichuris and hookworm epg, though not as effectively as for Ascaris [80, 81]. The chief disadvantage of drug treatment is rapid re-infection that necessitates repeated drug treatment to achieve lasting benefit.

Community-based control programs most frequently focus on delivery through the school system, as schoolaged children tend to have the highest intensity of infection, and delivery through the schools is more efficient than community-based or household distribution. In the Republic of Korea [82], nationwide screening of all schoolchildren followed by twice yearly anthelmintic treatment of all infected children between 1969 and 1995 reduced the nationwide Ascaris prevalence from 55.4 to $0.02 \%$. This remarkable reduction coincided with investment in infrastructure and a dramatic increase in the annual per capita GNP from USD 210 in 1969 to USD 10,315 in 1997, both of which would also have contributed to reduced transmission of Ascaris.

Although reports of drug resistance to human anthelmintics are rare, evidence of emerging resistance does exist. In Madagascar, treatment with levamisole every 2 months over 16 months successfully reduced Ascaris prevalence and intensity over the first 8 months [83], but both prevalence and egg output then increased, despite continued drug treatment every 2 months.

The cost of mass treatment programs can be reduced by using locally manufactured generic drugs, but quality control is needed. A comparison between albendazole from GlaxoSmithKline and two generics produced in Nepal showed that all three products were equally effective in reducing Ascaris epg but that cure rates were lower for one of the generics [84]. Reduced efficacy will not only hinder the effectiveness of the program, but it may also promote emergence of drug resistance.

Other cost-saving measures have been explored. In Vietnam, the cost per child of school-based treatment was reduced from USD 0.77 to 0.03 by improving efficiencies in distribution and teacher training, and also by eliminating the baseline survey and monitoring activities [71]. Although it is understandable that countries need to reduce the cost of these programs, the monitoring and evaluation side are essential, if changes in the frequency of drug treatment, in the preferred drug, or the need for alternative or additional interventions are incorporated in a timely manner. Without a monitoring program, poor efficacy of generics and emerging drug resistance may not be detected in a timely manner. 
Sanitation, Hygiene and Health Education

Remarkably, use of a latrine does not always reduce the prevalence or intensity of Ascaris. In tea plantations in Sri Lanka, the high fecal contamination of the environment due to indiscriminate defecation may override any benefit of using latrines [85]. Furthermore, eco-san latrines designed to produce a safe biosolid for application in agriculture can also be a source of contamination. In El Salvador, households that buried biosolids from eco-san latrines were 8.3 times more likely to be infected with $A s$ caris than those using pit latrines where biosolids were untouched [28].

In Uzbekistani households, promotion of hygienic behaviors (hand washing, safe disposal of feces and boiling of drinking water) through participatory methodologies was successful in reducing re-infection rates with intestinal parasites (including Ascaris) by $30 \%$ after a year, compared with treated children not benefiting from the educational intervention [86]. The risk of Ascaris, Trichuris and/or hookworm infection was elevated by 4.1 times in Pacific Island schools that did not have a water supply, regardless of water quality [19], highlighting the importance of access to water in schools. Interestingly, however, although regular washing of hands before eating reduced the prevalence of Ascaris among 176 subjects aged 2-50 years old from tea plantations in Sri Lanka, Ascaris intensity was unaffected by the source of water for drinking or bathing, by boiling drinking water, or by washing hands before eating and after defecation [85].

\section{Vaccines}

No vaccine against Ascaris is available, and it is likely to be many years before one is developed. However, in light of evidence that antibody responses to a recombinant form of a human Ascaris allergen (rABA-1A) are associated with reduced Ascaris epg (fig. 2,3) [34], and the promising results following experimental mucosal vaccination of pigs against $A$. suum [87], scientists remain hopeful.

\section{Removal of Ascaris Eggs from Water, Soil and Food}

A recent survey of Iranian water treatment plants revealed that wastewater treatment reduced the number of eggs to less than 1 helminth egg/liter [88], a level considered acceptable by WHO for irrigation purposes. Anaerobic digestion under thermophilic conditions for $30 \mathrm{~min}$ at $53-55^{\circ} \mathrm{C}$ has been shown to reduce A. suum egg numbers by threefold [89], but UV radiation has little effect [90]. Liming is commonly used, and several studies have considered the conditions needed for effective control. Capizzi-Banas et al. [91] were able to inactivate Ascaris eggs through liming for $75 \mathrm{~min}$ at $55^{\circ} \mathrm{C}$ or for $8 \mathrm{~min}$ at $60^{\circ} \mathrm{C}$. More recently, Bean et al. [92] showed that the process of liming whereby Ascaris eggs are exposed to high $\mathrm{pH}(12$ then 11.5) for up to $72 \mathrm{~h}$ at room temperature had no effect on viability. (Incidentally, they observed that this liming procedure reduced bacterial, viral and Giardia infectivity, but increased that of Cryptosporidium oocysts!) One factor often not considered in assessing conditions for inactivation is the ammonia concentration, as ammonia can reduce both the $\mathrm{pH}$ and temperature required to inactivate Ascaris eggs in sludge samples [93]. High temperature treatment can also generate manure safe for use as fertilizer; use of a biodrying compost system with forced aeration and temperatures that exceeded $55^{\circ} \mathrm{C}$ for 4 days prevented embryonation of Ascaris eggs [94].

Removing Ascaris eggs from food presents considerable challenges though recent work has shown that application of high hydrostatic pressure ( $<241 \mathrm{MPa}$ for $60 \mathrm{~s}$ ) prevented embryonation of $A$. suum eggs [95]. This opens a new possibility for killing eggs that have already contaminated food items.

\section{Concurrent Infections}

\section{Ascaris and Other Helminths}

Ascaris is rarely the only parasite in a population. Among pregnant women enrolled in a study in Uganda, $15 \%$ were HIV-positive, $15 \%$ had malaria, $38 \%$ had hookworm, $13 \%$ had Trichuris, $6 \%$ had Ascaris, $15 \%$ had Strongyloides, and 22\% had Mansonella perstans [96]. In addition, Ascaris is rarely the only parasite in an individual. As just one example, stool examinations in a communitywide survey of 1,240 people in Americaninhas, Brazil, revealed that over half the population had multiple intestinal helminths [44].

Concurrent infections within a single host may arise by chance. A survey of 1,370 children (6-11 years old) in Palestine [97] revealed that the two most common intestinal parasites, Ascaris (12.8\% prevalence) and Giardia (8.0\% prevalence), occurred together in $1.02 \%$ of children, exactly the percentage that would be expected by chance $(0.128 \times 0.08=0.0102)$. In many cases, however, concurrent infection cannot be explained by chance events. Based on a comprehensive set of data from 335 households in Brazil [98], triple infection with Ascaris, Schistosoma mansoni and hookworm occurred significantly more frequently than expected, as did dual infections with Ascaris and hookworm, and with Ascaris and $S$. mansoni. These dual combinations remained more 
Table 1. Comparison between observed and predicted frequency of single and multiple helminth infection among 1,332 individuals in Americaninhas, Minas Gerais, Brazil, in 2004 and odds ratio (adjusted by age group, sex, presence of other infections, and clustering by household) that the first listed parasite is associated with the second

\begin{tabular}{|c|c|c|c|c|c|c|}
\hline Species present & \multicolumn{2}{|c|}{ Percentage of population } & $\chi^{2}$ & Prob $>p$ & $\begin{array}{l}\text { Adjusted odds ratio } \\
(95 \% \mathrm{CI})\end{array}$ & Prob $>p$ \\
\hline Hookworm only & 11.4 & 20.6 & 41.6 & $<0.0001$ & & \\
\hline Schistosoma mansoni only & 4.6 & 8.0 & 13.4 & $<0.0001$ & & \\
\hline Ascaris with hookworm & 19.9 & 16.7 & 4.6 & 0.03 & $3.65(2.71-4.91)$ & $<0.001$ \\
\hline Ascaris, hookworm and S. mansoni & 19.0 & 13.8 & 13.0 & 0.0003 & & \\
\hline
\end{tabular}

Adapted from Fleming et al. [98], with permission.

common than expected even after adjustment for age, sex, household clustering and the presence of other infections as shown in table 1. Although the joint occurrence of Ascaris and S. mansoni was found more often than expected, fecal egg counts were lower for both species than when each species was present as a single infection, suggesting an antagonistic association [98]. Antagonistic associations have also been reported in pigs concurrently infected with A. suum and Trichinella spiralis [99].

Concurrent infections may arise from a common mode of transmission or from common household or genetic factors. The positive association between Ascaris and Trichuris observed by Ellis et al. [46] in China was explained by household factors that accounted for $32.7 \%$ of the risk of concurrent infection and by genetic makeup that explained $16.3 \%$ of the risk of multiple helminth infection (Ascaris and/or Trichuris and/or Schistosoma japonicum). Positive correlations between egg counts for all paired combinations of the soil-transmitted nematodes, Ascaris, Trichuris, and hookworm were reported in an Indian fishing village [21] and for Ascaris and Trichuris in Cameroon [43]. However, the positive association between Ascaris and Onchocerca in a village highly endemic for Ascaris [43] cannot be explained by a common route of transmission as Onchocerca is transmitted by the bite of a black fly.

\section{Ascaris and Malaria}

Since the 1970s there has been debate regarding the relationship between Ascaris infection and clinical malaria. Several, though not all $[45,100]$, recent studies provide evidence that Ascaris increases the risk of clinical malaria [100-103]. Children admitted to hospital in Senegal for severe clinical malaria had a significantly higher prevalence of Ascaris than age-matched controls from the community at large [102]. However, in southwest Uganda, where malaria is less common and where Ascaris prevalence and intensity are also relatively low, a community-wide survey revealed no evidence that infection with Ascaris (or other intestinal nematodes) influenced the occurrence of clinical malaria [45]. Most recently, a randomized trial in Madagascar examined the effect of repeated levamisole on Plasmodium falciparum density [83]. Levamisole treatment every 2 months significantly reduced Ascaris infection but increased $P$. falciparum density in blood smears in subjects 5 years of age and older. The authors suggested that the presence of Ascaris was beneficial in keeping malaria parasitemia down. A wide variety of factors differed among these studies, but nevertheless, the data suggest that further research is needed on the interaction between Ascaris and malaria, particularly as large scale anthelmintic campaigns are ongoing in many regions of the world.

\section{Ascaris and HIV}

Ascaris and other helminth infections are often present in HIV-seropositive individuals. In Honduras, for example, among 133 HIV-positive adults, 24\% were infected with Ascaris [104]. In Zambia, of 297 seropositive, asymptomatic adults, $13.1 \%$ were infected with Ascaris and $24.9 \%$ were infected with at least one helminth [105]. There is growing evidence that the Ascaris-induced Th2 environment is permissive for the establishment and proliferation of other infections, including HIV. For example, HIV-seropositive South Africans were more likely to recall having Ascaris infection as a child or to recall prior deworming than the seronegative comparison group [76]. However, no detectable association between Ascaris eggs 
Table 2. Impact of latrine type on prevalence of parasitic infection among 107 households in El Salvador

\begin{tabular}{|c|c|c|c|c|c|c|}
\hline $\begin{array}{l}\text { Type of latrine } \\
\text { (number of homes) }\end{array}$ & $\mathrm{n}$ & $\begin{array}{l}\text { Ascaris } \\
\text { lumbricoides }^{1}\end{array}$ & $\begin{array}{l}\text { Trichuris } \\
\text { trichiura }^{2}\end{array}$ & Hookworm $^{2}$ & $\begin{array}{l}\text { Giardia } \\
\text { lamblia }^{3}\end{array}$ & $\begin{array}{l}\text { Entamoeba } \\
\text { histolytica }^{4}\end{array}$ \\
\hline Double-vault desiccating (31) & 127 & $15.5(3.3-74.8)$ & $7.1(3.0-17.1)$ & $0.5(0.2-1.3)$ & $0.4(0.2-1.1)$ & $0.5(0.2-1.4)$ \\
\hline Pit (31) & 141 & $0.9(0.1-6.0)$ & $0.6(0.1-1.5)$ & $1.4(0.5-3.5)$ & $0.5(0.2-1.3)$ & $0.8(0.4-1.8)$ \\
\hline
\end{tabular}

Adjusted odds ratio $(95 \% \mathrm{CI})$ indicating the risk of infection relative to those using no latrine (25 homes). Significant odds ratios are shown in bold. Adapted from Corrales et al. [28], with permission.

${ }^{1}$ Adjusted for age, anthelmintic in previous 3 months, having a dirt floor, owning pigs.

2 Adjusted for age, anthelmintic in previous 3 months, having a dirt floor, type of water source.

${ }^{3}$ Adjusted for having a dirt floor, socioeconomic status, type of water source.

${ }^{4}$ Adjusted for overt signs of malnutrition and type of water source.

in stool and HIV seropositivity was detected among 907 adults from a villages in Tanzania [106]. These studies indicate that the interaction between Ascaris and HIV may be more related to a history of Ascaris infection than to current infection. Adams et al. [76] highlighted the importance of not relying only on Ascaris eggs in stool (current infection) when attempting to understand co-infection dynamics; this perspective was also shared by Schäfer et al. [62] and Fincham et al. [63] with regard to Ascaris, co-infection and allergy. They suggest that circulating antibody responses or other immunological conditions indicative of a history of exposure to Ascaris may be more relevant than current infection in explaining the occurrence (or absence) of other infections.

Helminths affect the immune response to HIV [107]. Of particular interest was the improvement in immune function following anthelmintic treatment of HIV-infected Ethiopians who migrated to Israel [108]. Despite tremendous advances in our understanding of immune responses to pathogens, it is clear that much more research is needed with regard to how pathogens respond to the variety of immunodominant situations generated by the presence of other pathogens.

\section{Impact of Concurrent Infections on Control Approaches}

\section{Recommended Type of Latrine}

New types of latrine are now available, and a recent study conducted in El Salvador has compared infection levels among households with no latrine to those using the standard pit latrine, or a solar desiccating latrine, or a double-vault desiccating latrine [28]. What is most striking about this research is that no one type of latrine was beneficial against both nematode and protozoan parasites (table 2) and, moreover, households using the double-vault desiccating latrine had a significantly higher prevalence of both Ascaris and Trichuris than those using no latrine. In addition, households that used biosolids from either of the desiccating latrines had elevated risk of infection with Trichuris, Giardia, and Entamoeba histolytica compared with those who buried the biosolids. Despite the evidence presented above that improvements in sanitation and hygiene may not always result in a detectable reduction in Ascaris infection in the shortterm $[28,85]$, such improvements tied with health education are considered essential for long-term control, and it is important that latrine design be optimized to reduce transmission of all fecally transmitted pathogens.

\section{Drug Interventions}

The widespread occurrence of concurrent infections has led policy makers to recommend drug interventions that target multiple parasitic infections at the same time. Recognizing that soil-transmitted helminths frequently co-occur with filarial infections and/or schistosomiasis, the Global Programme to Eliminate Lymphatic Filariasis combines albendazole with either ivermectin or diethylcarbanazine (DEC) if intestinal nematodes are present, and the Schistosomiasis and Soil-Transmitted Helminthiasis Control Programmes use praziquantel together with either albendazole or mebendazole [79]. Surprisingly few studies have examined the pharmacokinetics and side effects of co-administration of these drug combinations, but a review of the studies available to date indicates no reason for concern in the use of several of the 2-drug combinations [79].

Combination therapy provides many benefits, both in treating multiple infection and in reducing drug delivery 
costs. Drug combinations that are effective against Ascaris can improve compliance with treatments against other infections such as filariasis [109], because of the immediate expulsion of Ascaris worms in the feces. People see the expelled Ascaris, perceive removal of intestinal worms as a benefit, and thus are more inclined to comply with other treatments where obvious immediate benefits are not evident. The expulsion of Ascaris may also have a more direct benefit in controlling filarial infection. Sahoo et al. [110] hypothesize that the presence of intestinal worms acts to regulate filarial infection. They observed that albendazole treatment of subjects infected with both intestinal worms and filarial parasites significantly reduced levels of circulating filarial antigen, but that this effect was not observed in subjects who did not have intestinal worms at the time of treatment.

Oqueka et al. [111] followed the pattern of Ascaris infection status over 2 years of combined, yearly albendazole and DEC treatment. As expected, the prevalence of Ascaris dropped from 43.8 to $26.5 \%$ between 2002 and 2004 , demonstrating that infection had not returned to pre-intervention levels between treatments. Given the well-described tendency for predisposition, it would be expected that most of those who were infected with Ascaris in 2004 would also have been infected in 2002. However, when data on individuals were examined, more than half of those who were infected in 2004 had been uninfected in 2002. Although the authors do not report intensity data, it would be interesting to determine if, compared with use of albendazole alone, the combination of DEC and albendazole reduced the tendency for heavily infected individuals to become heavily re-infected.

As with any intervention, unexpected consequences need to be considered. In China, despite the decline in the prevalence of Ascaris, Trichuris and hookworm following a decade of control, a dramatic increase in Clonorchis and Taenia prevalence has occurred in some regions [112]. The reduced prevalence and intensity of Ascaris in the Republic of Korea [82] was associated with increased numbers of people infected with Clonorchis sinensis between 1997 and 2004, and the reemergence of vivax malaria over the past 15 years is also of some concern [82]. It is not clear whether the emergence of these infections was caused in some way by the reduction in nematode infections, but these observations highlight the need for adaptive management of such programs.

\section{Vaccination}

Given the endemic, chronic nature of Ascaris that begins at a very young age, many people in Ascaris-endem- ic areas are likely to be infected throughout much of their lives. There is mounting evidence that the Th2-biased immune environment induced by Ascaris (and other helminth infections) may influence their ability to respond appropriately to vaccinations. For example, albendazole treatment in a group of pregnant Ugandan women infected with hookworms and other helminths significantly reduced the IFN- $\gamma$ response following BCG vaccination of their infants [95], indicating that hookworm infection of mothers may suppress immune responses to vaccines administered to their infants. Ascaris infection was very low in this population (prevalence of only 6\%), so the study was unable to make conclusions on whether Ascaris might have similar effects to hookworm. However, a recent vaccination study in pigs demonstrated that the presence of $A$. suum reduced the efficacy of vaccination against Mycoplasma hyopneumoniae [113]. Given the important implications for the success of vaccination programs, it is remarkable that more research has not been conducted on the potentially critical role of Ascaris and other helminth infections on development of immune responses following vaccination.

\section{More Comprehensive Intervention Packages}

Interventions that target bacterial infections together with helminths have received recent attention through the efforts of Hotez et al. [2] who argue that there is a complex of 'neglected tropical diseases' that can be effectively controlled as a group through combined administration of anthelmintic drugs, albendazole, praziquantel and ivermectin, along with the antibiotic azithromycin. It is their premise that control of these neglected infections (among which they include Ascaris) will be beneficial in efforts to manage malaria, tuberculosis and HIV/ AIDS, particularly because of the evidence that co-infection with one or more of the 'neglected' diseases alters the outcome of the 'big three'.

Micronutrient supplementation is another intervention that is frequently combined with deworming. This combination attacks the infection-malnutrition cycle from two angles, with the intent of removing existing parasites and also improving the ability of the child to resist future infections by boosting the immune response [27, 73-74]. Other forms of comprehensive interventions include conditional transfer programs whereby poor families receive cash supplements or food vouchers in return for ensuring that their children are dewormed regularly, that they are vaccinated and that they attend school [114; a detailed review of the interactions between multiple nutritional deficiencies and infections is beyond the scope of this review, but see 69, 70]. 
As more is understood about the wide range of interactions among infectious agents, nutritional and immunological status, and broader environmental and social determinants of health, it will become clearer that integrated health programs are desperately needed.

\section{Research Priorities and Conclusion}

Based on this review of the recent literature, there is an urgent need for further research in the following areas.

\section{Water Resource Management and Latrines}

The provision of safe drinking water to resource-poor communities is becoming more difficult as water scarcity is increasing. Simple, cost-effective methods for the treatment of wastewater are urgently needed if we are to prevent the rates of transmission of Ascaris and other fecal pathogens that may be transferred onto crops from increasing, not decreasing. Improvements in the design of latrines that prevent transmission of the range of fecal pathogens is still needed as some of the currently tested latrines may increase the risk of transmission of certain infections $[28,85]$.

\section{Role of Pigs}

Given the recent report that cross-transmission of Ascaris from pigs to humans occurs more frequently than previously believed [31], further molecular studies on larger samples of sympatric pig and human ascarid populations are needed to confirm the suspected high rate of hybridization. Much more attention is needed to prevent human contamination with pig feces.

\section{Geospatial Patterns and Modeling Spatial Dynamics}

The recent advances involving geographic information systems and remote sensing provide a tremendous opportunity to provide both regional and local scale monitoring and predictions. This will allow a combination of temporal and spatial analyses that can provide important insights into the changing pattern of concurrent infections - something that would have been relatively intractable just a decade ago.

\section{Interaction between Immune Responses and \\ Molecular Genetics of the Host}

The cascade of immunological and inflammatory markers that are induced in response to Ascaris infection in humans remains poorly understood. We have barely begun to understand the role that host genetics may play in explaining why some individuals are more susceptible to infection than others. We know very little about how an infant responds to the first Ascaris infection and how these responses vary over the continuing cycle of repeated re-infection through childhood. We know virtually nothing about the response of the elderly to Ascaris. Without an understanding of the link between current infection intensity, history of infection, and immune responses, it will be difficult to tease apart the effect of $A s$ caris (or removal of Ascaris) on susceptibility to other infections or to efficacy of vaccines.

\section{Concurrent Infections and Their Interactions -}

A New Research Agenda

It is becoming very clear that a complex dynamic interplay exists among the various pathogens that infect an individual and the host response to these pathogens, and that a pathogen-specific focus may be insufficient. However, expanding to a more holistic view of the set of pathogens in an individual will place considerable demands on the research community. It will require large interdisciplinary teams who have experience in HIV, malaria, tuberculosis, intestinal nematodes, diarrheal disease, filarial infections, schistosomiasis, food-borne digeneans, skin diseases, respiratory infections, and allergy, to name just a few. The research team should also include epidemiologists, immunologists, nutritionists, statisticians and modelers if sense is to be made of the data. Such research will also require a different funding regime from that usually available, because of the wide range of assays and expertise required.

\section{A Systems Level Approach for Design of Integrated Control Strategies}

Upon recognizing the community of interacting parasites within an individual, it becomes obvious that programs designed to control one infection at a time should be discouraged. Rather, comprehensive attention to several infections and to environmental, biophysical and social factors that put individuals at risk of infection should be the norm. The design of such programs requires research that captures not only the wide scope of potential benefits to the health and well-being of the community, but also the potential negative consequences that may emerge when trying to solve one set of problems. It also requires integration of expertise of environmental biologists, and social and cognitive scientists who are able to work with the communities and the biomedical scientists to ensure that the planning, monitoring and adaptive management of the interventions is optimized. 


\section{Concluding Thoughts}

Ascaris remains the most common parasitic infection in the world. Although it is not a major cause of mortality, relative to other infections, its impact on the health of children has been well known for decades. However, evidence now exists that Ascaris infection modifies the immuno- logical environment within an individual host to be protective against certain conditions, but permissive to others, with implications not only for the health of children but also of adults. Furthermore, the presence of Ascaris may reduce the efficacy of vaccines. Thus, this review highlights the fact that control of Ascaris may have a greater public health significance than previously understood.

\section{References}

$>1$ Crompton DWT: Ascaris and ascariasis. Adv $>13$ Luoba AI, Geissler PW, Estambale B, et al: GeParasitol 2001;48:285-375.

2 Hotez PJ, Molyneux DH, Fenwick A, et al: Incorporating a rapid-impact package for neglected tropical diseases with programs for HIV/AIDS, tuberculosis, and malaria. PLoS Medicine 2006;3:e102.

$\checkmark 3$ O'Lorcain P, Holland CV: The public health importance of Ascaris lumbricoides. Parasitology 2000;121:S51-S71.

$\checkmark 4$ Dickson R, Awasthi S, Williamson P, et al: Effects of treatment for intestinal helminth infection on growth and cognitive performance in children: systemic review of randomised trials. BMJ 2000;320:1697-1701.

$>5$ Ezeamama AE, Freidman JF, Acosta LP, et al: Helminth infection and cognitive impairment among Filipino children. Am J Trop Med Hyg 2005;72:540-548.

$\checkmark 6$ Hall A, Holland C: Geographical variation in Ascaris lumbricoides fecundity and its implications for helminth control. Parasitol Today 2000;16:540-544.

$>7$ Quilès F, Balandier J-Y, Capizzi-Banas S: In situ characterisation of a microorganism surface by Raman microspectroscopy: the shell of Ascaris eggs. Anal Bioanal Chem 2006;386:249-255.

$>8$ Getachew S, Gebre-Michael T, Erko B, et al: Non-biting cyclorrhaphan flies (Diptera) as carriers of intestinal human parasites in slum areas of Addis Ababa, Ethiopia. Acta Trop 2007;103:186-194.

$>9$ Tatfeng YM, Usuanlele MU, Orukpe A, et al: Mechanical transmission of pathogenic organisms: the role of cockroaches. J Vect Borne Dis 2005;42:129-134.

- 10 Uneke CJ, Ogbu O: Potential for parasite and bacteria transmission by paper currency in Nigeria. J Environ Health 2007;69:54-60.

11 Wong MS, Bundy DAP, Golden MHN: The rate of ingestion of Ascaris lumbricoides and Trichuris trichiura eggs in soil and its relationship to infection in two children's homes in Jamaica. Trans R Soc Trop Med Hyg 1991; 85:89-91.

$>12$ Saathoff E, Olsen A, Kvalsvig JD, et al: Ecological covariates of Ascaris lumbricoides infection in schoolchildren from rural KwaZulu-Natal, South Africa. Trop Med Int Health 2005;10:412-422. ophagy among pregnant and lactating women in Bondo District, western Kenya. Trans R Soc Trop Med Hyg 2004;98:734-741.

14 Luoba AI, Geissler PW, Estambale B, et al: Earth-eating and reinfection with intestinal helminths among pregnant and lactating women in western Kenya. Trop Med Int Health 2005; 10:220-227.

15 Adams VJ, Markus MB, Adams JFA, et al: Paradoxical helminthiasis and giardiasis in Cape Town, South Africa: epidemiology and control. Afr Health Sci 2005;5:276-280.

16 Omahmid O, Bouboum K: Assessment of the health hazards associated with wastewater reuse: transmission of geohelminthic infections (Marrakech, Morroco). Int J Environ Health Res 2005;15:127-133.

17 Amoah P, Drechsel P, Abaidoo RC, Ntow WJ: Pesticide and pathogen contamination of vegetables in Ghana's urban markets. Arch Environ Contam Toxicol 2006;50:1-6.

18 Fortes B de PMD, Ortiz Valencia LI, Ribeiro $\mathrm{S}$ do V, Medronho R de A: Modelagem geoestatística da infecção por Ascaris lumbricoides. Cad Saúde Pública 2004;20:727-734.

19 Hughes RG, Sharp DS, Hughes MC, et al: Environmental influences on helminthiasis and nutritional status among Pacific schoolchildren. Int J Environ Health Res 2004;14: 163-177.

20 Traub RJ, Robertson ID, Irwin P, et al: The prevalence, intensities and risk factors associated with geohelminth infection in teagrowing communities of Assam, India. Trop Med Int Health 2004;9:688-701.

21 Naish S, McCarthy J, Williams GM: Prevalence, intensity and risk factors for soiltransmitted helminth infection in a south Indian fishing village. Acta Trop 2004;91: 177-187.

22 Quihui L, Valencia ME, Crompton DWT, et al: Role of the employment status and education of mothers in the prevalence of intestinal parasitic infections in Mexican rural schoolchildren. BMC Public Health 2006; $6: 225$.
23 Rinne S, Rodas EJ, Galer-Unti R, et al: Prevalence and risk factors for protozoan and nematode infections among children in an Ecuadorian highland community. Trans R Soc Trop Med Hyg 2005;99:585-592.

24 Carvalho-Costa FA, Gonçalves AQ, Lassanci SL, et al: Giardia lamblia and other intestinal parasitic infections and their relationships with nutritional status in children in Brazilian Amazon. Rev Inst Med Trop Sao Paulo 2007;49:147-153.

25 Steinmann P, Zhou X-N, Li Y-L, et al: Helminth infections and risk factor analysis among residents in Eryuan county, Yunnan province, China. Acta Trop 2007;104:38-51.

-26 Quihui-Cota L, Valencia ME, Crompton DW, et al: Prevalence and intensity of intestinal parasitic infections in relation to nutritional status in Mexican schoolchildren. Trans R Soc Trop Med Hyg 2004;98:653659.

27 Payne LG, Koski KG, Ortega-Barria E, Scott ME: Benefit of vitamin A supplementation on Ascaris reinfection is less evident in stunted children. J Nutr 2007;137:1455-1459.

28 Corrales LF, Izurieta R, Moe CL: Association between intestinal parasitic infections and type of sanitation system in rural El Salvador. Trop Med Int Health 2006;11:18211831.

-29 Olsen A, Permin A, Roepstorff A: Chicken and pigs as transport hosts for Ascaris, Trichuris and Oesophagostomum eggs. Parasitology 2001;123:325-330.

30 Peng W, Yuan K, Hu M, Gasser RB: Recent insights into the epidemiology and genetics of Ascaris in China using molecular tools. Parasitology 2007;134:325-330.

31 Criscione CD, Anderson JD, Sudimack D, et al: Disentangling hybridization and host colonization in parasitic roundworms of humans and pigs. Proc Biol Sci 2007;274:26692677.

32 Goodman D, Haji HJ, Bickle QD, et al: A comparison of methods for detecting the eggs of Ascaris, Trichuris, and hookworm in infant stool, and the epidemiology of infection in Zanzibari infants. Am J Trop Med Hyg 2007;76:725-731. 
33 Anderson RM, May RM: Infectious Diseases of Humans: Dynamics and Control. Oxford, Oxford University Press, 1991.

-34 Turner JD, Faulkner H, Kamgno J, et al: Allergen-specific IgE and IgG4 are markers of resistance and susceptibility in a human intestinal nematode infection. Microbes Infect 2005;7:990-996.

-35 Galvani AP: Age-dependent epidemiological patterns and strain diversity in helminth parasites. J Parasitol 2005;91:24-30.

36 El Kettani S, Azzouzi EM: Prévalence des helminthes au sein d'une population rurale utilisant les eaux usées à des fins agricoles à Settat (Maroc). Cahiers Santé 2006;16:245251.

-37 Brooker S, Michael E: The potential of geographical information systems and remote sensing in the epidemiology and control of human helminth infections. Adv Parasitol 2000;47:245-288.

38 Brooker S, Clements ACA, Bundy DAP: Global epidemiology, ecology and control of soil-transmitted helminth infections. Adv Parasitol 2006;62:221-261.

-39 Brooker S, Kabatereine NB, Tukahebwa EM, Kazibwe F: Spatial analysis of the distribution of intestinal nematode infections in Uganda. Epidemiol Infect 2004;132:10651071.

-40 Gunawardena GSA, Karunaweera ND, Ismail MM: Wet-days: are they better indicators of Ascaris infection levels? J Helminthol 2004;78:305-310.

41 Guernier V, Hochberg ME, Guégan J-F: Ecology drives the worldwide distribution of human diseases. PLoS Biol 2004;2:e141.

-42 Barbosa CS, Favre TC, Wanderley TN, et al: Assessment of schistosomiasis, through school surveys, in the Forest Zone of Pernambuco, Brazil. Mem Inst Oswaldo Cruz 2006;101(suppl 1):55-62.

43 Faulkner H, Turner J, Behnke J, et al: Associations between filarial and gastrointestinal nematodes. Trans R Soc Trop Med Hyg 2005; 99:301-312.

-44 Brooker S, Alexander N, Geiger S, et al: Contrasting patterns in the small-scale heterogeneity of human helminth infections in urban and rural environments in Brazil. Int J Parasitol 2006;36:1143-1151.

-45 Shapiro AE, Tukahebwa EM, Kasten J, et al: Epidemiology of helminth infections and their relationship with clinical malaria in southwest Uganda. Trans R Soc Trop Med Hyg 2005;99:18-24.

-46 Ellis MK, Raso G, Li Y-S, et al: Familial aggregation of human susceptibility to co- and multiple helminth infections in a population from the Poyang Lake region, China. Int J Parasitol 2007;37:1153-1161.

-47 Williams-Blangero S, Subedi J, Upadhayay $\mathrm{RP}$, et al: Genetic analysis of susceptibility to infection with Ascaris lumbricoides. Am J Trop Med Hyg 1999;60:921-926.
48 Williams-Blangero S, VandeBerg JL, Subedi $\mathrm{J}$, et al: Genes on chromosomes 1 and 13 have significant effects on Ascaris infection. Proc Natl Acad Sci USA 2002;99:5533-5538.

49 Williams-Blangero S, Corrêa-Oliveira R, Vandeberg JL, et al: Genetic influences on plasma cytokine variation in a parasitized population. Hum Biol 2004;76:515-525.

50 Moller M, Gravenor MB, Roberts SE, et al: Genetic haplotypes of Th-2 immune signalling link allergy to enhanced protection to parasitic worms. Hum Mol Gen 2007;16: 1828-1836.

51 Churcher TS, Ferguson NM, Basáñez MG: Density dependence and overdispersion in the transmission of helminth parasites. Parasitology 2005;131:121-132.

52 Chan L, Bundy DAP, Kan SP: Aggregation and predisposition to Ascaris lumbricoides and Trichuris trichiura at the familial level. Trans R Soc Trop Med Hyg 1994;88:46-48.

53 Malla N, Fomda BA, Thokar MA: Serum cytokine levels in human ascariasis and toxocariasis. Parasitol Res 2006;98:345-348.

54 Bradley JE, Jackson JA: Immunity, immunoregulation and the ecology of trichuriasis and ascariasis. Parasite Immunol 2004;26: 429-441.

55 King E-M, Kim HT, Dang NT, et al: Immuno-epidemiology of Ascaris lumbricoides infection in a high transmission community: antibody responses and their impact on current and future infection intensity. Parasite Immunol 2005;27:89-96.

56 Turner JD, Faulkner H, Kamgno J, et al: Th2 cytokines are associated with reduced worm burdens in a human intestinal helminth in fection. J Infect Dis 2003;188:1768-1775.

57 Jackson JA, Turner JD, Rentoul L, et al: T helper cell type 2 responsiveness predicts future susceptibility to gastrointestinal nematodes in humans. J Infect Dis 2004;190: 1804-1811.

58 Jackson JA, Turner JD, Rentoul L, et al: Cytokine response profiles predict species-specific infection patterns in human GI nematodes. Int J Parasitol 2004;34:1237-1244.

59 van Riet E, Wuhrer M, Wahyuni S, et al: Antibody responses to Ascaris-derived proteins and glycolipids: the role of phosphorylcholine. Parasite Immunol 2006;28:363-371.

-60 Silva SR, Jacysyn JF, Macedo MS, FaquimMauro EL: Immunosuppressive components of Ascaris suum down-regulate expression of costimulatory molecules and function of antigen-presenting cells via an IL-10-mediated mechanism. Eur J Immunol 2006;36:32273237.

61 Oshiro TM, Enobe CS, Araújo CA, et al: PAS-1, a protein affinity purified from $A s$ caris suum worms maintains the ability to modulate the immune response to a bystander antigen. Immunol Cell Biol 2006;84: $138-144$.
62 Schäfer T, Meyer T, Ring J, et al: Worm infestation and the negative association with eczema (atopic/nonatopic) and allergic sensitization. Allergy 2005;60:1014-1020.

63 Fincham JE, Markus MB, van der Merwe L, et al: Ascaris, co-infection and allergy: the importance of analysis based on immunological variables rather than egg excretion. Trans R Soc Trop Med Hyg 2007; 101:680682

64 Obihara CC, Beyers N, Gie RP, et al: Respiratory atopic disease, Ascaris-immunoglobulin E and tuberculin testing in urban South African children. Clin Exp Allergy 2006;36: 640-648.

65 Cooper PJ, Chico ME, Rodrigues LC, et al: Reduced risk of atopy among school-age children infected with geohelminth parasites in a rural area of the tropics. J Allergy Clin Immunol 2003;111:995-1000.

66 Schopf L, Luccioli S, Bundoc V, et al: Differential modulation of allergic eye disease by chronic and acute Ascaris infection. Invest Ophthalmol Vis Sci 2005;46:2772-2780.

67 Leonardi-Bee J, Pritchard D, Britton J: Asthma and current intestinal parasite infection: systematic review and meta-analysis. Am J Respir Crit Care Med 2006;174:514-523.

68 Arruda LK, Santos ABR: Immunologic responses to common antigens in helminthic infections and allergic disease. Curr Opin Allergy Clin Immunol 2005;5:399-402.

-69 Koski KG, Scott ME: Gastrointestinal nematodes, nutrition and immunity: breaking the negative spiral. Annu Rev Nutr 2001;21:297321.

70 Crompton DWT, Nesheim MC: Nutritional impact of intestinal helminthiasis during the human life cycle. Annu Rev Nutr 2002;22: 35-59.

71 Cleary JD, Graham D, Lushbaugh WB, et al: Single low-dose mebendazole administered quarterly for Ascaris treatment. Am J Med Sci 2007;333:340-345.

72 Montresor A, Cong DT, Anh TL, et al: Cost containment in a school deworming programme targeting over 2.7 million children in Vietnam. Trans R Soc Trop Med Hyg 2007; 101:461-464.

73 Long KZ, Estrada-Garcia T, Rosado JL, et al: The effect of vitamin A supplementation on the intestinal immune response in Mexican children is modified by pathogen infections and diarrhea. J Nutr 2006;136:1365-1370.

-74 Stoltzfus RJ, Chway HM, Montresor A, et al: Low dose daily iron supplementation improves iron status and appetite but not anemia, whereas quarterly anthelmintic treatment improves growth, appetite and anemia in Zanzibari preschool children. J Nutr 2004; 134:348-356.

75 Odongo-Aginya EI, Kabatereine N, Ludwig $S$, et al: Substitution of malachite green with nigrosin - eosin yellow stain in the KatoKatz method: microscopical appearance of the helminth eggs. Afr Health Sci 2007;7:3336. 
-76 Adams VJ, Markus MB, Kwitshana ZL, et al: Recall of intestinal helminthiasis by HIV-infected South Africans and avoidance of possible misinterpretation of egg excretion in worm/HIV co-infection analyses. BMC Infect Dis 2006;6:88.

-77 Pecson BM, Barrios JA, Johnson DR, Nelson KL: A real-time PCR method for quantifying viable Ascaris eggs using the first internally transcribed spacer region of ribosomal DNA. Appl Environ Microbiol 2006;72:78647872 .

78 Albonico M, Montresor A, Crompton DW, Savioli L: Intervention for the control of soiltransmitted helminthiasis in the community. Adv Parasitol 2006;61:311-348.

79 Olsen A: Efficacy and safety of drug combinations in the treatment of schistosomiasis, soil-transmitted helminthiasis, lymphatic filariasis and onchocerciasis. Trans R Soc Trop Med Hyg 2007;101:747-758.

$\checkmark 80$ Adams VJ, Lombard CJ, Dhansay MA, et al: Efficacy of albendazole against the whipworm Trichuris trichiura - a randomised, controlled trial. S Afr Med J 2004;94:972976.

-81 Saathoff E, Olsen A, Kvalsvig JD, Appleton CC: Patterns of geohelminth infection, impact of albendazole treatment and re-infection after treatment in schoolchildren from rural KwaZulu-Natal/South-Africa. BMC Infect Dis 2004;4:27.

82 Hong S-T, Chai J-Y, Choi M-H, et al: A successful experience of soil-transmitted helminth control in the Republic of Korea. Korean J Parasitol 2006;44:177-185.

83 Brutus L, Watier L, Briand V, et al: Parasitic co-infections: does Ascaris lumbricoides protect against Plasmodium falciparum infection? Am J Trop Med Hyg 2006;75:194198.

84 Albonico M, Mathema P, Montresor A, et al: Comparative study of the quality and efficacy of originator and generic albendazole for mass treatment of soil-transmitted nematode infections in Nepal. Trans R Soc Trop Med Hyg 2007;101:454-460.

-85 Gunawardena GSA, Karunaweera ND, Ismail MM: Socio-economic and behavioural factors affecting the prevalence of Ascaris infection in a low-country tea plantation in Sri Lanka. Ann Trop Med Parasitol 2004;98: 615-621.

86 Gungoren B, Latipov R, Regallet G, Musabaev E: Effect of hygiene promotion on the risk of reinfection rate of intestinal parasites in children in rural Uzbekistan. Trans R Soc Trop Med Hyg 2007;101:546-569.

87 Tsuji N, Miyoshi T, Islam MK, et al: Recombinant Ascaris 16-kilodalton protein-induced protection against Ascaris suum larval migration after intranasal vaccination in pigs. J Infect Dis 2004;190:1812-1820.

$>88$ Mahvi AH, Kia EB: Helminth eggs in raw and treated wastewater in the Islamic Republic of Iran. East Med Health J 2006;12:137143.
89 Aitken MD, Sobsey MD, Blauth KE, et al: Inactivation of Ascaris suum and poliovirus in biosolids under thermophilic anaerobic digestion conditions. Environ Sci Technol 2005;39:5804-5809.

90 Brownwell SA, Nelson KL: Inactivation of single-celled Ascaris suum eggs by lowpressure UV radiation. Appl Environ Microbiol 2006;72:2178-2184.

-91 Capizzi-Banas S, Deloge M, Remy M, Schwartzbrod J: Liming as an advanced treatment for sludge sanitisation: helminth eggs elimination - Ascaris eggs as model. Water Res 2004;38:3251-3258.

$\$ 2$ Bean CL, Hansen JJ, Margolin AB, et al: Class $\mathrm{B}$ alkaline stabilization to achieve pathogen inactivation. Int J Environ Res Public Health 2007;4:53-60.

-93 Pecson BM, Barrios JA, Jinénez BE, Nelson KL: The effects of temperature, $\mathrm{pH}$, and ammonia concentration on the inactivation of Ascaris eggs in sewage sludge. Water Res 2007;41:2893-2902.

$\checkmark 94$ Collick AS, Inglis S, Wright P, et al: Inactivation of Ascaris suum in a biodrying compost system. J Environ Qual 2007;36:15281533.

95 Rosypal AC, Bowman DD, Holliman D, et al: Effects of high hydrostatic pressure on embryonation of Ascaris suum eggs. Vet Parasitol 2007;145:86-89.

$\$ 66$ Elliott AM, Namujju PB, Mawa PA, et al, 'Mother and Baby' Study Team: A randomized controlled trial of the effects of albendazole in pregnancy on maternal responses to mycobacterial antigens and infant responses to bacilli Calmette-Guérin (BCG) immunisation. BMC Infect Dis 2005;5: 115.

$\$ 97$ Astal Z: Epidemiological survey of the prevalence of parasites among children in Khan Younis governorate, Palestine. Parasitol Res 2004;94:449-451.

98 Fleming FM, Brooker S, Geiger SM, et al: Synergistic associations between hookworm and other helminth species in a rural community in Brazil. Trop Med Int Health 2006;11:56-64.

99 Frontera E, Alcaide M, Boes J, et al: Concurrent infection with Trichinella spiralis and other helminths in pigs. Vet Parasitol 2007; 146:50-57.

100 Nacher M: Interactions between worm infection and malaria. Clin Rev Allergy Immunol 2004;26:85-92.

101 Spiegel A, Tall A, Raphenon G, et al: Increased frequency of malaria attacks in subjects co-infected by intestinal worms and Plasmodium falciparum malaria. Trans R Soc Trop Med Hyg 2003;97:198-199.
102 Le Hesran J-Y, Akiana J, Ndiaye EHM, et al: Severe malaria attack is associated with high prevalence of Ascaris lumbricoides infection among children in rural Senegal. Trans R Soc Trop Med Hyg 2004;98:397399.

103 Druilhe P, Tall A, Sokhna C: Worms can worsen malaria: towards a new means to roll back malaria? Trends Parasitol 2005;21: 359-362.

104 Kaminsky RG, Soto RJ, Campa A, Baum MK: Intestinal parasitic infections and eosinophilia in an human immunedeficiency virus positive population in Honduras. Mem Inst Oswaldo Cruz 2004;99:773-778.

105 Modjarrad K, Zulu I, Redden DT, et al: Prevalence and predictors of intestinal helminth infections among human immunodeficiency virus type-1 infected adults in an urban African setting. Am J Trop Med Hyg 2005; 73:777-782.

106 Nielsen NO, Simonsen PE, Magnussen P, et al: Cross-sectional relationship between HIV, lymphatic filariasis and other parasitic infections in adults in coastal northeastern Tanzania. Trans R Soc Trop Med Hyg 2006; 100:543-550.

107 Fincham JE, Markus MB, Adams VJ: Could control of soil-transmitted helminthic infection influence the HIV/AIDS pandemic. Acta Trop 2003;86:315-333.

108 Borkow G, Weisman Z, Leng Q, et al: Helminths, human immunodeficiency virus and tuberculosis. Scand J Infect Dis 2001; 33:568-571.

109 De Rochars MB, Direny AN, Roberts JM, et al: Community-wide reduction in prevalence and intensity of intestinal helminths as a collateral benefit of lymphatic filariasis elimination programs. Am J Trop Med Hyg 2004;71:466-470.

110 Sahoo PK, Satapathy AK, Michael E, Ravindran B: Concomitant parasitism: bancroftian filariasis and intestinal helminths and response to albendazole. Am J Trop Med Hyg 2005;73:877-880.

111 Oqueka T, Supali T, Ismid IS, et al: Impact of two rounds of mass drug administration using diethylcarbamazine combined with albendazole on the prevalence of Brugia timori and of intestinal helminths on Alor Island, Indonesia. Filaria J 2005;4:5.

112 Coordinating Office of the National Survey on the Important Parasitic Diseases: A national survey on current status of the important parasitic diseases in human population (in Chinese). Zhongguo Ji Sheng Chong Xue Yu Ji Sheng Chong Bing Za Zhi 2005;23(suppl):332-340.

113 Urban JF Jr, Steenhard NR, Solano-Aguilar GI, et al: Infection with parasitic nematodes confounds vaccination efficacy. Vet Parasitol 2007;148:14-20.

114 Huerta MC: Child health in rural Mexico: has PROGRESA reduced children's morbidity risks? Social Policy Admin 2006;40: 652-677. 